\title{
Comparative analysis of Cd-responsive maize and rice transcriptomes highlights Cd co-modulated orthologs
}

\author{
Dan Cheng ${ }^{\dagger}$, Mingpu Tan ${ }^{* \dagger} \mathbb{B}$, Haijuan Yu, Liang Li, Dandan Zhu, Yahua Chen and Mingyi Jiang
}

\begin{abstract}
Background: Metal tolerance is often an integrative result of metal uptake and distribution, which are fine-tuned by a network of signaling cascades and metal transporters. Thus, with the goal of advancing the molecular understanding of such metal homeostatic mechanisms, comparative RNAseq-based transcriptome analysis was conducted to dissect differentially expressed genes (DEGs) in maize roots exposed to cadmium (Cd) stress.
\end{abstract}

Results: To unveil conserved Cd-responsive genes in cereal plants, the obtained 5166 maize DEGs were compared with $2567 \mathrm{Cd}$-regulated orthologs in rice roots, and this comparison generated 880 universal Cd-responsive orthologs groups composed of 1074 maize DEGs and 981 rice counterparts. More importantly, most of the orthologous DEGs showed coordinated expression pattern between $\mathrm{Cd}$-treated maize and rice, and these include one large orthologs group of pleiotropic drug resistance (PDR)-type ABC transporters, two clusters of amino acid transporters, and 3 blocks of multidrug and toxic compound extrusion (MATE) efflux family transporters, and 3 clusters of heavy metal-associated domain (HMAD) isoprenylated plant proteins (HIPPs), as well as all 4 groups of zinc/iron regulated transporter protein (ZIPs). Additionally, several blocks of tandem maize paralogs, such as germin-like proteins (GLPS), phenylalanine ammonia-lyases (PALs) and several enzymes involved in JA biosynthesis, displayed consistent co-expression pattern under $\mathrm{Cd}$ stress. Out of the 1074 maize DEGs, approximately 30 maize Cd-responsive genes such as ZmHIPP27, stress-responsive NAC transcription factor (ZmSNAC1) and 9-cis-epoxycarotenoid dioxygenase (NCED, vp14) were also common stress-responsive genes reported to be uniformly regulated by multiple abiotic stresses. Moreover, the aforementioned three promising $\mathrm{Cd}$ upregulated genes with rice counterparts were identified to be novel $\mathrm{Cd}$-responsive genes in maize.

Meanwhile, one maize glutamate decarboxylase (ZmGAD1) with Cd co-modulated rice ortholog was selected for further analysis of $\mathrm{Cd}$ tolerance via heterologous expression, and the results suggest that ZmGAD1 can confer $\mathrm{Cd}$ tolerance in yeast and tobacco leaves.

Conclusions: These novel findings revealed the conserved function of Cd-responsive orthologs and paralogs, which would be valuable for elucidating the genetic basis of the plant response to $\mathrm{Cd}$ stress and unraveling Cd tolerance genes.

\section{Background}

Cadmium $(\mathrm{Cd})$ is one of the most hazardous heavy metals, however it can be absorbed by the roots from the soil and transported to the aboveground parts, thus indirectly induces oxidative stress and negatively affects nutrient uptake and homeostasis, eventually causes stunted growth and reductions in productivity of crop plants [1].

\footnotetext{
* Correspondence: tempo@njau.edu.cn

${ }^{\dagger}$ Dan Cheng and Mingpu Tan contributed equally to this work.

National Key Laboratory of Crop Genetics and Germplasm Enhancement,

College of Life Sciences, Nanjing Agricultural University, Nanjing, China
}

Therefore, it is critically important to understand the mechanisms underlying $\mathrm{Cd}$ uptake, translocation and accumulation in plants.

Generally, Cd uptake and allocation is associated with a number of metal-regulated transporters including heavy metal ATPase (HMA), ATP-binding cassette transporters $(A B C)$ subfamilies $A B C C$ and $A B C G$, natural resistance-associated macrophage protein (Nramp), and zinc/iron regulated transporter protein (ZIP), which are indispensable for the homeostasis of essential metals [2-8]. 
Despite the identification of those genes, the underlying knowledge of molecular mechanisms for plant $\mathrm{Cd}$ tolerance is still fragmental. Using RNAseq profiling approach, thousands of genes involved in Cd uptake, translocation and detoxification have been identified in several plant species, such as radish [9], pakchoi [7], perennial herb [10], $\mathrm{Zn} / \mathrm{Cd}$ hyperaccumulator Sedum alfredii Hance [11], fast growing Cd-resistant tree [12], dwarf Polish wheat [13], and sweet sorghum [14]. Recently, RNAseq studies allowed the identification of long non-coding RNAs and cis-natural antisense transcription in response to $\mathrm{Cd}$ stress in rice $[15,16]$.

Comparative intrageneric transcriptomic analyses have been used for revealing the mechanisms of $\mathrm{Cd}$ tolerance in plants $[6,7,17]$. For instance, RNAseq-based approach was utilized to unveil transcriptomic changes in maize seedlings roots under Cd stress $[18,19]$. Of those DEGs in maize, some functional genes encoding stress and defense responses related proteins, transporters and transcription factors displayed great differential alteration in Mo17 and B73, and 115 genes were co-modulated in both genotypes across three time points [19].

Concerning the $\mathrm{Cd}$ responses in model cereals, the genome-wide RNAseq-based transcriptome profiling has been explored in rice [20-24]. As for the other model cereal maize, a few RNAseq-based transcriptomic studies focusing on Cd-responsive genes have been conducted $[18,19]$. However, to the best of our knowledge, there is no report on the identification of universal cereal $\mathrm{Cd}$-responsive genes, in other words, $\mathrm{Cd}$ co-modulated orthologs between maize and rice. Consequently, the common regulatory system for cereal crops in response to $\mathrm{Cd}$ is largely unknown and remains an essential issue to be addressed.

In the current study, we firstly implemented the Tophat-Cufflinks pipeline to identify early Cd-responsive DEGs in maize and rice seedlings roots. To ascertain our results of early transcriptomic response to $\mathrm{Cd}$ exposure, we compared Cd-regulated 5166 DEGs in maize with their 2567 counterparts in rice using plant orthologs annotation information, therefore the coordinated expression of cereal orthologs as well as maize paralogs was unveiled. After that, the Cd-responsive maize orthologs with synergistically Cd-regulated rice counterparts were queried against multiple stress common-responsive gene sets, and $\sim 30$ DEGs in the intersection are of particular interest, including those encoding HMAD isoprenylated protein ZmHIPP27, transcription factor ZmSNAC1, and key enzyme for ABA synthesis. Further Cd-tolerance assay in yeast and tobacco leaves indicated that $\mathrm{ZmGAD1}$, which had Cd co-modulated rice ortholog, exhibited Cd tolerance in the host cells. These results could lead to a comprehensive understanding of the genetic basis of the plant response to $\mathrm{Cd}$ stress and open prospective for excavating novel genes and for the genetic improvement of plant tolerance to Cd stress.

\section{Methods}

\section{Plant material and treatments}

Seedlings of maize (Zea mays L. inbred line B73) were cultivated using a hydroponic system in a growth chamber under the conditions as described previously [24]. For Cd treatment, the trifoliate seedlings were transferred into fresh growing solutions containing $100 \mu \mathrm{M} \mathrm{CdCl} \mathrm{Cl}_{2}$. After $1 \mathrm{~h}$ of Cd treatment, maize seedlings roots were sampled for RNAseq analysis as described previously $[20,24]$.

\section{RNAseq libraries preparation and sequencing}

Total RNA for RNAseq was extracted from maize seedling roots using a plant RNA kit (Omega, USA) according to the manufacturer's instructions, and total RNA samples with two biological replicates were sent to Biomarker Corporation (www.biomarker.com.cn) for RNAseq library preparation and sequencing as described previously [24].

After the adaptor and low-quality sequences of pair-end reads were trimmed, a total of $38.71 \mathrm{~Gb}$ clean data from $6 \mathrm{cDNA}$ libraries were obtained and all sequence reads have been deposited in the NCBI SRA datasets (www.ncbi.nlm.nih.gov/sra) under the accession number SRP115510. Over $80 \%$ of the clean reads had scores at the Q30 level (Additional file 1: Table S1).

\section{Mapping pair-end reads to the reference genome}

The 'Tuxedo' packages TopHat-Cufflinks were utilized to process the RNAseq data [24, 25]. The B73 reference genome file ZmB73_RefGen_v2 and gene model annotation file ZmB73_5b_FGS.gff were downloaded from MaizeSequence (ftp://ftp.maizesequence.org/pub/maize/release-5b) directly. The expression values were represented by fragments per kilobase transcript per million reads mapped (FPKM), and the differential expression analysis of genes and transcripts across two conditions was performed using the Cuffdiff utility. Fold-change $\geq 1.5$ and q_value $\leq 0.05$ was set as the threshold to determine the DEGs between each set of compared samples as described previously [24].

MapMan (v3.6.0 RC1) was employed to annotate and subsequently visualize the stress-related DEGs on metabolic pathways [26].

For processing Cd-treated rice roots RNAseq data (www.ncbi.nlm.nih.gov/sra/SRP053169), the rice reference genome and gene model annotation files (MSU6) were downloaded from Illumina's iGenomes project (support.illumina.com/sequencing/sequencing software/igenome.html) directly, and the packages TopHat-Cufflinks were employed as described above. 


\section{RNA isolation and CDNA synthesis for cloning gene coding sequence}

Total RNA was extracted from plant material using the RNAiso Plus (TaKaRa Bio Inc., China) according to the manufacturer's instructions. Approximately $2 \mu \mathrm{g}$ of total RNA was reverse transcribed using oligo $d(T)_{16}$ primer and M-MLV reverse transcriptase (TaKaRa). The synthesized cDNA was used for amplifying the coding sequences (CDS) of ZmGADs.

Transcript levels of randomly selected 10 genes were measured by qRT-PCR using a DNA Engine Opticon 2 real-time PCR detection system (Bio-Rad) with SYBR Premix Ex Taq (TaKaRa). The expression level of each target gene was normalized against that of ZmActin in maize. The primers used in the qRT-PCR experiments are listed in Additional file 2: Table S2.

\section{Yeast expression vector construction and cd-tolerance assay in yeast}

To investigate whether ZmGADs confer Cd-tolerance in yeast, we subcloned the coding sequences of maize ZmGADs gene into the yeast expression vector $p Y E S 2$ with the primers listed in Additional file 2: Table S2.

Then the ZmGADs recombinant plasmid and pYES2 empty vector (EV) were transformed into $\mathrm{Cd}$-sensitive yeast $\Delta y c f 1$ mutant cells using the lithium acetate transformation method, and the isogenic yeast wild-type BY4741(MATa; ura3 $\Delta 0$; leu $2 \Delta 0$; his $3 \Delta 1$; met15 $\Delta 0$ ) transformed with $\mathrm{EV}$ was used as a control [27-29].

Positive colonies were selected on synthetic dropout (SD) plates containing the appropriate selective markers (minimal medium lacking Uracil, designated as SD-Ura). Yeast strains expressing EV or ZmGADs were pre-cultured in SD-Ura liquid medium at $30^{\circ} \mathrm{C}$ for $16 \mathrm{~h}$. Pre-cultured cells were diluted to an $\mathrm{OD}_{600}$ of 1.0 , and $10-\mu \mathrm{L}$ aliquots were spotted onto SD-Ura agar medium with or without $40 \mu \mathrm{M}$ $\mathrm{CdCl}_{2}$ in the presence of $2 \%$ galactose. The test plates were incubated at $30^{\circ} \mathrm{C}$ for 3 days, then the growth of clones transformed with ZmGADs was compared with $\Delta y c f 1$ cells transformed with the EV on the same plates supplied with Cd ions $[27,29,30]$.

Next, single clones that survived on the $\mathrm{Cd}$-containing plates were selected and cultured in SD-Ura liquid medium supplemented with $30 \mu \mathrm{M}$ $\mathrm{CdCl}_{2}$ and $2 \%$ galactose $[27,29,30]$. The growth of ZmGADs transformant was determined through measuring $\mathrm{OD}_{600}$ every $12 \mathrm{~h}$, and the EV transformed Cd-sensitive $\Delta y c f 1$ and the wild-type counterparts BY4741yeast cells were considered as controls in each experiment [31].

All drop-test experiments and growth turbidity assays were independently repeated at least three times.

\section{Agro-infiltration and cd response in tobacco leaves}

The coding sequences of ZmGADs were amplified and inserted into the binary vector pCAMBIA1300-GFP. Agro-infiltration and $\mathrm{Cd}$ tolerance Assays was performed based on previous reports [32-35], with minor modifications.

Agrobacterium tumefaciens strain GV3101 was transformed with ZmGADs constructs and then grown in Luria-Bertani culture medium supplemented with appropriate antibiotics. After $36-48 \mathrm{~h}$, A tumefaciens cells were spun down by centrifugation, and re-suspended in Agro-infiltration buffer $\left(10 \mathrm{mM} \mathrm{MgCl}_{2}\right.$ and $10 \mathrm{mM}$ 2-[N-morpholino] ethanesulfonic acid [MES], pH 5.6). The re-suspended $A$. tumefaciens cells were diluted and mixed with P19 silencing suppressor in a 1:1 to a final $\mathrm{OD}_{600}=0.3$ for each construct before infiltrating into the leaves of 3-4 week-old tobacco (Nicotiana benthamiana) plants.

After $3 \mathrm{~d}$ of agro-infiltration, tobacco leaves transiently expressing ZmGAD-GFP fusion proteins were analyzed using confocal fluorescence microscopy to monitor transformation. For fluorescence observations, patches were cut from tobacco leaves $3 \mathrm{~d}$ after agro-infiltration and used for confocal imaging on a Zeiss LSM 710 confocal laser scanning microscope. RFP-H2A, localized in the nucleus, was used to mark the nuclei [36]. GFP fluorescence was excited by the $488 \mathrm{~nm}$ line of an argon laser, and emissions were detected between 500 and $530 \mathrm{~nm}$.

After 3 days of agro-infiltration, the needle hole in the leaves expressing ZmGAD- GFPs were re-infiltrated with $500 \mu \mathrm{M} \mathrm{Cd}\left(\mathrm{NO}_{3}\right)_{2}$. The infected leaves were photographed at 4 days post-treatment.

Each experiment was repeated at least three times with a minimum of 10 infected leaves. Leaf regions transiently expressing EV were used as a control.

\section{Results \\ Functional characterization of early cd-responsive differentially expressed genes (DEGs) in maize roots}

To investigate transcripts that were specifically regulated in short-term Cd stressed maize roots, RNAseq data from replicated samples were processed through TopHat-Cufflinks pipeline to perform pair-wise comparisons between $1 \mathrm{~h} \mathrm{Cd}$-treated $(\mathrm{Cd} 1 \mathrm{~h})$ and untreated (ck1h) maize seedlings (Additional file 1: Table S1).

Using a moderate cutoff (fold change>1.5 and q_value $\leq 0.05$ ), a total of 5166 genes were identified as being early $\mathrm{Cd}$-responsive differentially expressed genes (DEGs), of which 3715 were Cd-induced and 1451 were Cd-repressed in maize seedlings roots (Additional file 3: Table S3). However, only 239 DEGs were in the intersection of these 5166 and the available $768 \mathrm{Cd}$-responsive genes in B73 or Mo17 across three time points reported previously [19] (Additional 
file 3: Table S3). The expression pattern of randomly selected 10 DEGs was basically consistent with that of qRT-PCR validation (Additional file 4: Table S4), which suggested that DEGs resulted from RNAseq are credible for further analysis.

To gain insights into the functionality of the 5166 DEGs that are likely to be associated with the Cd response, all of these Cd-responsive transcripts were functionally grouped and visualized in the candidate pathway networks with MapMan software.

Among the DEGs within the 'TF' group, 9 members of $\mathrm{C} 2 \mathrm{C} 2(\mathrm{Zn}) \mathrm{DOF}$ zinc finger family, 11 HSFs (including those in the subcategory "heat" of 'Stress' group), 11 members of Triple-Helix TFs family, and the majority of EREBP and NAC as well as WRKY family TFs were upregulated in response to $\mathrm{Cd}$ (Fig. 1, Table 1).

Of the transcripts mapped to 'Hormones' category, 17 genes (including 7 lipoxygenase LOX, 5 allene oxidase synthase AOS, one allene oxidase cyclase and four 12-oxophytodienoate reductases OPR) for jasmonate synthesis, and 6 genes for brassinosteroid metabolism and signaling were also upregulated by $\mathrm{Cd}$ treatment. With regard to 'Stress' response, all 6 genes in response to cold and almost all genes responsive to drought/salt were upregulated post $\mathrm{Cd}$ treatment. In addition, almost all pectin esterases and genes for cell wall precursor synthesis in 'Cell wall' category were upregulated in response to $\mathrm{Cd}$ (Fig. 1, Table 1).

In contrast, all mapped 4 nuclear transcription factors (NF-Y) of CCAAT box binding factor family, 5 chromatin remodeling factors, and 4 members in SET-domain transcriptional regulator family were uniformly downregulated by $\mathrm{Cd}$ treatment (Fig. 1, Additional file 3: Table S3).

\section{Conserved cd-responsive orthologous genes in maize and rice roots}

To date, no comprehensive list of maize genes orthologous to rice genes involved in $\mathrm{Cd}$ stress response is available. Therefore, the global comparison of the DEGs identified in the short-term $\mathrm{Cd}$ treated maize and rice roots (NCBI-SRA SRP053169, Additional file 5: Table S5) was performed with the aid of plant model organism orthologs annotation [37, 38].

This comparison output $1074 \mathrm{Cd}$-responsive maize orthologs of 981 rice genes, which can be categorized

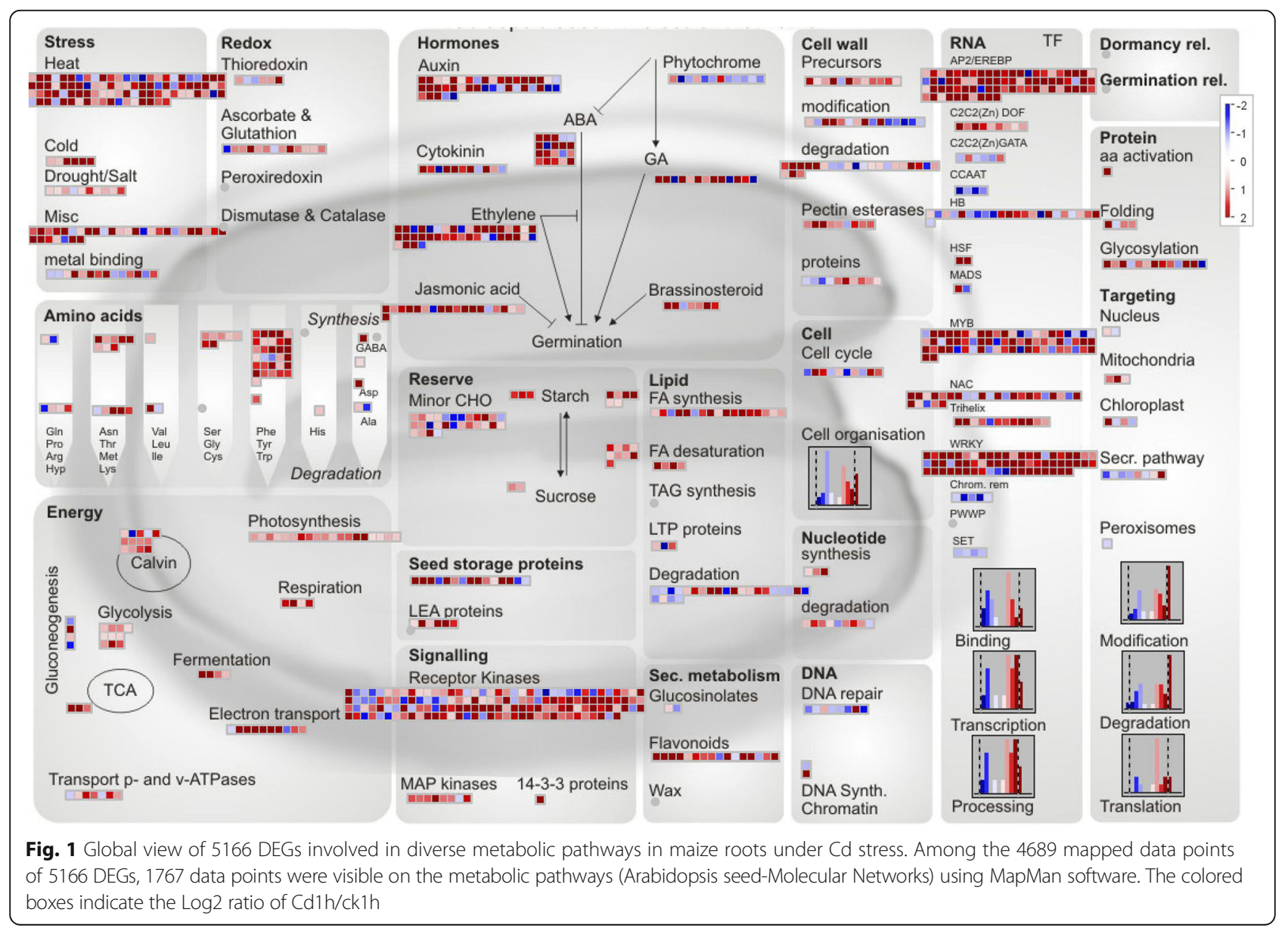


Table 1 The function classification of maize DEGs with rice orthologs

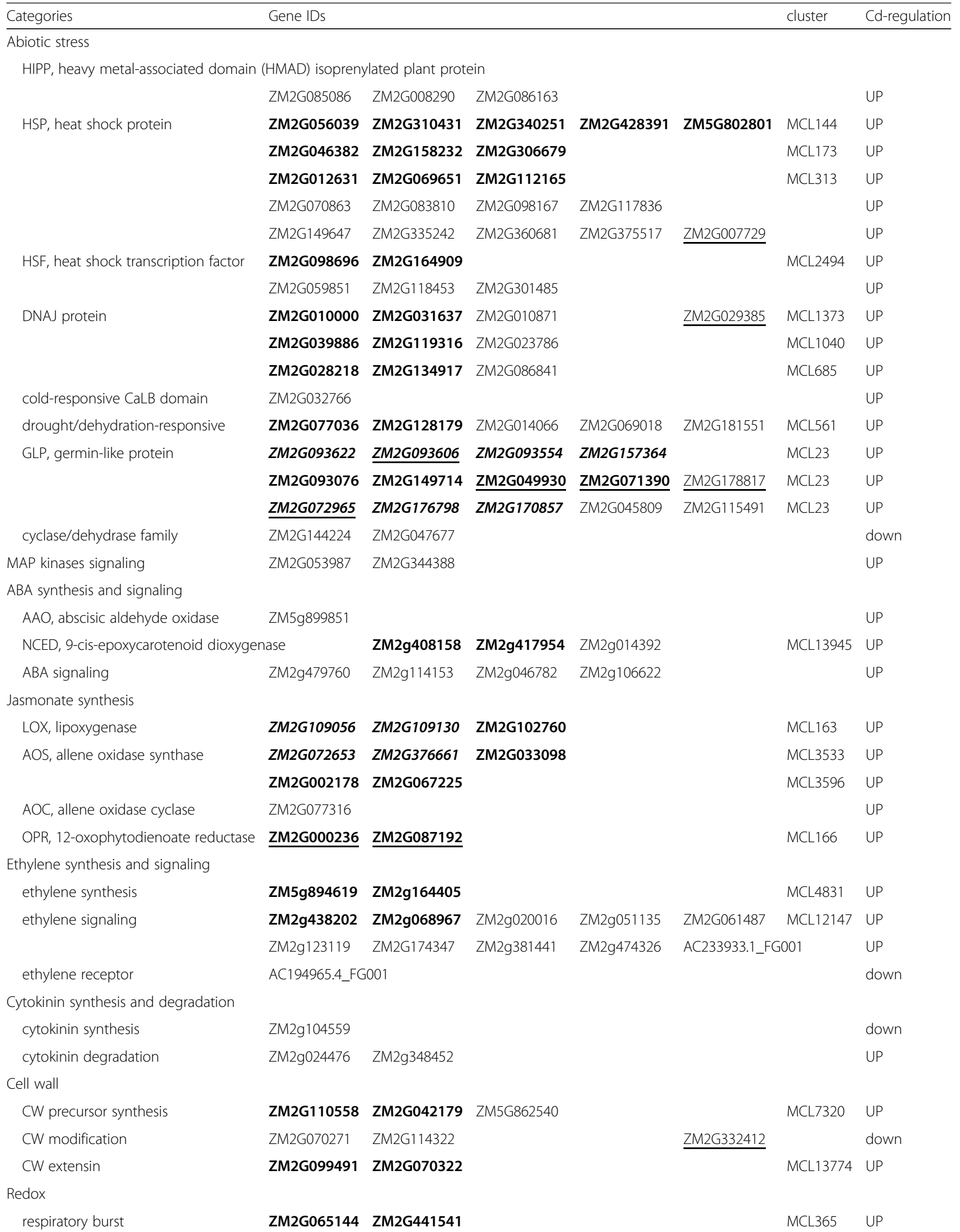


Table 1 The function classification of maize DEGs with rice orthologs (Continued)

\begin{tabular}{|c|c|c|c|c|c|c|c|}
\hline Categories & Gene IDs & & & & & cluster & Cd-regulation \\
\hline AsA and GSH cycling & ZM2G134708 & ZM2G141376 & & & & & UP \\
\hline glutaredoxins & ZM2G178886 & ZM2G311898 & ZM2G148387 & & & MCL631 & UP \\
\hline GST, glutathione S-transferases & ZM2G052625 & ZM2G308687 & ZM2G161827 & ZM2G161891 & ZM2G044383 & & UP \\
\hline & ZM2G025190 & ZM2G146913 & ZM2G175134 & ZM2G475059 & & & UP \\
\hline minor $\mathrm{CHO}$ metabolism & & & & & & & \\
\hline raffinose family synthases & ZM2G077181 & ZM2G340656 & ZM2G165919 & & & MCL3328 & UP \\
\hline trehalose synthesis & ZM2G014729 & ZM2G117564 & ZM2G112830 & & & MCL11250 & UP \\
\hline Development & & & & & & & \\
\hline patatin-like storage proteins & ZM2G114036 & ZM2G414047 & & & ZM2G117378 & MCL12549 & UP \\
\hline & ZM2G091956 & ZM2G124921 & & & & MCL12894 & UP \\
\hline LEA, late embryogenesis abundant & ZM2G099003 & ZM2G093418 & & & & & UP \\
\hline Secondary metabolism & & & & & & & \\
\hline isoprenoids & ZM2G150367 & & & & & & UP \\
\hline phenylpropanoids & ZM2G060210 & ZM2G108714 & & & & MCL12214 & UP \\
\hline & ZM2G114918 & ZM2G061806 & ZM2G064969 & ZM2G140996 & & MCL16463 & UP \\
\hline & ZM2G165192 & ZM2G125448 & ZM2G362298 & ZM5G882427 & & & UP \\
\hline lignin biosynthesis. PAL phenylalanine & & ZM2G029048 & ZM2G334660 & ZM2G170692 & & MCL71 & UP \\
\hline & & ZM2G081582 & ZM2G063917 & ZM2G118345 & & MCL71 & UP \\
\hline lignin biosynthesis. Others & ZM2G167613 & ZM2G100158 & ZM2G125448 & AC234163.1_FG & 002 & & UP \\
\hline flavonoids and anthocyanins & ZM2G117246 & ZM2G382785 & ZM2G099467 & ZM5G881887 & ZM2G051683 & & UP \\
\hline
\end{tabular}

DEGs within the same orthologs group are in bold, while paralogous DEGs are in italic. DEGs underlined are also Cd-responsive reported previously [19]. Plant orthologous group prefix APK_ORTHOMCL is abbreviated as MCL

into 880 plant orthologous groups (APK_ORTHOMCL abbreviated as MCL, Table 1, Additional file 6: Table S6). For the 1074 maize DEGs having differentially expressed counterparts in rice, 939 were upregulated and 135 downregulated by $\mathrm{Cd}$ stress in maize roots (Table 2, Additional file 6: Table S6, Additional file 7: Figure S1). Moreover, 80 of them are in the list of 768 $\mathrm{Cd}$-responsive genes in $\mathrm{B} 73$ or Mo17 roots under various Cd pressures [19]. Conversely, 994 maize DEGs with rice counterparts were not stated as $\mathrm{Cd}$-responsive genes previously (Additional file 6: Table S6). Among the 80 universal Cd-responsive DEGs, 4 GLP members in group MCL23, 2 patatin-like members of MCL12549, and two 12-oxo-phytodienoic acid reductases (ZM2G000236 and ZM2G087192 designated as ZmOPR2 and ZmOPR5, respectively) in cluster MCL166 were also significantly upregulated in both maize genotypes (Table 1) [19].

To further explore the common regulatory mechanisms in maize and rice under $\mathrm{Cd}$ stress, these $\mathrm{Cd}$-responsive orthologs were investigated their involvement in various metabolic pathways. According to the global function view of these Cd-responsive orthologs in MapMan, the majority of them were upregulated in response to $\mathrm{Cd}$, whether in maize or in rice roots (Additional file 7: Figure S1).
Apparently, the uniformly upregulated DEGs were enriched in abiotic stress response (heat, cold and drought/salt), hormone metabolism and signaling (ABA, ethylene and JA), cell wall precursors biosynthesis, as well as several TFs families (e.g. EREBP, NAC and WRKY).

Interestingly, the majority of mapped maize Cd-responsive orthologs can be categorized into orthologous clusters and exhibit group co-regulated manner. Particularly, Cd-induced germin-like protein (GLP) genes are concentrated on MCL23, while all $6 \mathrm{Cd}$-induced members of phenylalanine ammonia-lyase (PAL) belong to group MCL71 (Table 1, Fig. 1). Moreover, 9 GLPs of MCL23 cluster on chromosome 4. Out of this subset of 9 GLPs, both 4 members (ZM2G093622, ZM2G093606, ZM2G09 3554 and ZM2G157364) and other 3 members (ZM 2G072965, ZM2G176798 and ZM2G170857) are sorted in tandem, and one gap (about $127 \mathrm{~kb}$ ) separated these two GLPs blocks. Similarly, two PALs (ZM2G029048 and ZM2G334660) and two patatin-like storage proteins (ZM2G124921 and ZM2G091956) are tandem paralogs on chromosome 5 , chromosome 2, respectively, while two LOXs (ZM2G109056 and ZM2G109130) together with two AOSs (ZM2G072653 and ZM2G376661) are tandem paralogs on chromosome 1. Additionally, another two 
Table 2 Cd-regulated DEGs of orthologous transporters in maize and rice roots

BinName Maize Rice

Plant Orthologous

Groups

Gene ID Log2FC Annotation

Gene ID

$\log 2$ FC Annotation

APK_ORTHOMCL

Metal binding, chelation and storage

$\begin{array}{lll}\text { ZM2G085086 } & 2.43 & \begin{array}{l}\text { ZmHIPP27, HMAD isoprenylated } \\ \text { plant protein }\end{array} \\ \text { ZM2G008290 } & 3.75 & \text { ZmHIPP35 } \\ \text { ZM2G086163 } & 4.51 & \text { ZmHIPP36 }\end{array}$

Os04g17100 3.62

heavy metal-associated

MCL4978

Os10g30450 0.93

domain (HMAD), OSHIPP42

MCL1350

Os03g05750 7.38

OsHIPP35

MCL16487

$A B C$ transporters and multidrug resistance systems

\begin{tabular}{|c|c|c|}
\hline ZM5G874955 & 5.87 & $\begin{array}{l}\text { ABC transporter } G \text { family } \\
\text { member } 40\end{array}$ \\
\hline ZM5G892675 & 5.00 & $\begin{array}{l}\text { ABC transporter } G \text { family } \\
\text { member } 36\end{array}$ \\
\hline ZM2G003411 & 2.64 & $\begin{array}{l}\text { ABC transporter } G \text { family } \\
\text { member } 39\end{array}$ \\
\hline ZM2G366146 & 2.32 & $\begin{array}{l}\text { ABC transporter } G \text { family } \\
\text { member } 42\end{array}$ \\
\hline ZM2G143139 & 2.22 & $\begin{array}{l}\text { ABC transporter } G \text { family } \\
\text { member } 37\end{array}$ \\
\hline ZM2G415529 & 1.27 & $\begin{array}{l}\text { ABC transporter G family } \\
\text { member } 43 \text {-like }\end{array}$ \\
\hline ZM2G391815 & 1.23 & $\begin{array}{l}\text { ABC transporter } G \text { family } \\
\text { member } 34\end{array}$ \\
\hline \multicolumn{3}{|c|}{ cations transporters } \\
\hline ZM2G118821 & -0.92 & ZmIRT1, zinc transporter 10 \\
\hline ZM2G045849 & -1.05 & ZmZIP3, zinc transporter 1 \\
\hline ZM2G015955 & -0.94 & ZmZIP7, zinc transporter 4 \\
\hline ZM2G047762 & -0.81 & ZmZIP9, zinc transporter 5 \\
\hline ZM2G144083 & -1.83 & $\begin{array}{l}\text { ATP dependent copper } \\
\text { transporter }\end{array}$ \\
\hline
\end{tabular}

Os01g42380 2.15

ABCG36/OsPDR9, pleiotropic

MCL2

Os01g42410 2.59 drug resistance protein

Os02g11760 3.10

ABCG37/OsPDR8

MCL2

Os01g42370 1.68

ABCG39/OsPDR7

MCL2

Os08g29570 4.72

ABCG35/OsPDR11

MCL2

ABCG44/OsPDR17

MCL2

MCL2

MCL2

Divalent cations transporters

Os03g46470 -2.58

OsIRT1, Iron-regulated transporter

MCL3982

Os05g39540 -1.93

OsZIP9, ZRT/IRT-like protein

MCL386

Os06g37010 -1.39

OsZIP10

MCL2136

Os05g39560 -1.98

OsZIP5

MCL14115

Os04g46940 -0.99

OsHMA5, heavy metal P-type ATPase

MCL2236

Amino acid transporters

$\begin{array}{lll}\text { ZM2G164814 } & 2.35 & \text { amino acid carrier } \\ \text { ZM2G157168 } & 3.72 & \text { amino acid permease 2 } \\ \text { ZM2G433162 } & 1.46 & \text { amino acid permease 2 }\end{array}$

$\begin{array}{ll}\text { Os01g66010 } & 1.48 \\ \text { Os05g34980 } & 0.99 \\ \text { Os12g08090 } & 2.73 \\ \text { Os12g08130 } & 1.65\end{array}$

amino acid transporter

MCL399

amino acid transporter

MCL399

amino acid transporter

MCL2026

amino acid transporter

MCL2026

MATE efflux family and other transporters

$\begin{array}{lll}\frac{\text { ZM2G031938 }}{2.37} & \text { protein DETOXIFICATION } 40 \\ \text { ZM2G170128 } & 0.92 & \text { transparent testa 12 protein } \\ \text { ZM2G151903 } & 1.93 & \text { Protein DETOXIFICATION } 21 \\ \frac{\text { ZM2G079127 }}{2.00} & 2.00 & \text { Protein DETOXIFICATION } 21 \\ \text { ZM2G006212 } & 3.31 & \text { protein DETOXIFICATION 49 } \\ \text { ZM2G080992 } & 2.96 & \text { protein DETOXIFICATION 49 } \\ \text { ZM2G135175 } & 2.86 & \text { protein DETOXIFICATION 49 } \\ \text { ZM2G119970 } & 5.08 & \text { adenine/guanine permease AZG1 } \\ \text { ZM2G358791 } & 2.03 & \text { adenine/guanine permease AZG2 } \\ \text { ZM2G068220 } & 0.80 & \text { adenine/guanine permease AZG2 }\end{array}$

Os03g37490 $0.99 \quad$ PEZ1, Phenolic Efflux Transporter

MCL409

MCL409

Os12g03260 1.53

MATE efflux family protein

MCL636

Os02g45380 2.76

MCL636

Os04g48290 1.14

MCL1103

MCL1103

MCL1103

Os05g26840 1.05

permease domain

MCL6695

Os11g24060 1.01

permease domain

MCL7794

MCL7794 
Cd-responsive patatin-like storage proteins (ZM2G114036 and ZM2G414047) reported previously [19] are reverse tandem paralogs on chromosome 1 (Table 1).

According to the transport overview, the orthologs of mapped transporters displayed concordant expression pattern in Cd-treated maize and rice roots (Table 2). One orthologous group of PDR-type ABC transporters (MCL2), two groups of amino acid transporters, and 3 groups of MATE efflux family transporters as well as 3 groups of HMAD isoprenylated proteins (HIPPs) were all rapidly upregulated in Cd-treated maize and rice roots. However, all 4 orthologous groups of ZRT/IRTlike transporter proteins (ZIPs) and one orthologous group of $\mathrm{Cu}$ transporter were downregulated concomitantly by $\mathrm{Cd}$ stress in both species, indicating a certain level of conservation in $\mathrm{Cd}$ response (Table 2, Additional file 3: Table S3, Additional file 5: Table S5).

However, it is noteworthy that 25 of the 28 Cd-responsive maize transporters with co-modulated rice orthologs were not demonstrated as Cd-responsive genes previously (Table 2).

\section{Common stress-responsive genes in maize}

To ascertain whether these conserved Cd-responsive maize genes are involved in diverse stress response, they are compared with those identified in previous RNAseq analysis of maize seedlings subjected to drought, salinity and cold [39, 40]. Remarkably, out of 1074 Cd-responsive maize DEGs with rice counterparts, about 30 genes are also in the list of DEGs response to these abiotic stresses, and they can be grouped into 5 categories. With respect to those located in 'abiotic stress', ZmHIPP27 and Lea5-D-like are particularly noteworthy. Regarding 'transcription factors', ZmSNAC1, 6 ERFs including two DREBs, two zinc finger proteins, and WRKY40 were all common stress-responsive genes. Among those related to 'Phytohormone and signaling,' $v p 14$ encoding NCED is responsible for ABA biosynthesis, meanwhile, auxin-induced in root cultures AIR12, ZIM transcription factor, and gibberellin receptor GID1 are involved in auxin, JA, and GA signaling, respectively. Moreover, $v p 14$ has been repetitiously identified to be common stress-responsive maize gene in previous reports (Table 3 ).

Taking 'Cell wall' into account, two common stress-responsive genes encode UDP-glucuronate 4-epimerase and one gene code cellulose synthase. Besides these 4 categories, the category 'Posttranslational modification' containing 4 common stress-responsive genes is of particular interest.

Among the 30 common stress-responsive genes, only ZM2G172230 encoding CaseinoLytic Protease (ClpD) and ZM2G328785 coding receptor protein kinase (ZmPK1), both in the category 'Posttranslational modification', were also reported to be steadily induced by $\mathrm{Cd}$ treatments across several time points (Table 3) [19].

ZmGADs confer cd tolerance in cd-sensitive yeast mutant To unveil novel Cd-tolerant genes from the Cd-responsive orthologs in maize, the key enzyme responsible for $\gamma$-aminobutyric acid (GABA) synthesis named glutamate decarboxylase (GAD) was selected, since Cd-regulated GAD orthologs in maize and rice were mapped to GABA biosynthesis pathway coincidentally (Fig. 1, Additional file 7: Figure S1).

It is noteworthy that ZmGAD1 (ZM2G098875) and its ortholog OsGAD3 (Os03g13300), within the orthologs group MCL1496, were all upregulated by Cd stress, with the $\log _{2} \mathrm{FC}$ of 2.7 and 0.84 , respectively (Additional file 3: Table S3, Additional file 5: Table S5, Additional file 6: Table S6). These results illustrate that key genes involved in GABA biosynthesis are uniformly stimulated in maize and rice roots under $\mathrm{Cd}$ stress.

To establish a close link between GABA and Cd-tolerance, maize ZmGAD1 and ZmGAD2 (ZM5G8 26838) within the same orthologous group MCL1496 were cloned into the yeast expression vector pYES2 and retransformed to $\mathrm{Cd}$-sensitive yeast $\Delta y c f 1$ cells to test whether ZmGADs can complement $\Delta y c f 1$ phenotype, thus confirming their functionality of Cd-tolerance.

The dilution spot tests and turbidity growth assays showed that the $\Delta y c f 1$ mutant transformed with $Z m G A D s$ exhibited dramatically enhanced growth when compared with $\Delta y c f 1$ cells transformed with the pYES2 empty vector (EV) under the Cd pressure (Fig. 2a, b).

\section{ZmGADs confer cd tolerance in tobacco cells via a transient assay}

To assess the validity of the results from yeast complementation assay, tobacco leaves-based in planta transient analysis was used. To ascertain whether these $\mathrm{Cd}$ tolerant genes confer $\mathrm{Cd}$ tolerance in planta, we initially introduced two GAD-green fluorescent protein (GFP) fusion pSuper-1300 constructs into tobacco leaf cells by agro-infiltration. The results showed that GFP-tagged ZmGAD1 and ZmGAD2 fused proteins accumulated in tobacco leaves $3 \mathrm{~d}$ post infiltration, meanwhile, the subcellular localization assay indicated that all these 2 GFP fused proteins were localized in cytoplasm and nucleus (Fig. 3a).

To assess the functional relevance of GADs in maize against $\mathrm{Cd}$ stress, tobacco leaves transiently expressing them validated above were treated by infiltrating $\mathrm{Cd}$ solution, and the leaf regions transiently expressing EV were used as a control. The results showed that the EV transformed control regions showed chlorosis and lesions $4 \mathrm{~d}$ after $\mathrm{Cd}$ treatment, indicative of a symptom of $\mathrm{Cd}$ toxicity. However, lesions on leaves transiently expressing ZmGADs 
Table 3 The expression of common stress-responsive maize genes and their rice orthologs in plant roots exposed to Cd treatment

\begin{tabular}{|c|c|c|c|c|c|c|}
\hline \multirow{2}{*}{$\begin{array}{l}\text { Categories } \\
\text { Gene ID }\end{array}$} & \multicolumn{3}{|l|}{ Maize } & \multicolumn{2}{|l|}{ Rice } & \multirow{2}{*}{$\begin{array}{l}\text { Plant Orthologous } \\
\text { Groups } \\
\text { ORTHOMCL }\end{array}$} \\
\hline & $\log 2 F C$ & maize Annotation & Gene ID & $\log 2 \mathrm{FC}$ & rice Annotation & \\
\hline \multicolumn{7}{|l|}{ Abiotic stress } \\
\hline ZM2G085086 & 2.4 & $\begin{array}{l}\text { ZmHIPP27, HMAD isoprenylated } \\
\text { protein }\end{array}$ & Os04g17100 & 3.6 & $\begin{array}{l}\text { heavy metal-associated domain } \\
\text { (HMAD) OsHIPP42 }\end{array}$ & MCL4978 \\
\hline ZM2G099003 & 2.6 & Lea5-D-like & Os01g21250 & 2.3 & $\begin{array}{l}\text { LEA, late embryogenesis } \\
\text { abundant protein }\end{array}$ & MCL16656 \\
\hline ZM2G012631 & 0.9 & HSP9O-2 & Os08g39140 & 1.5 & heat shock protein & MCL313 \\
\hline ZM2G032766 & 2.7 & CaLB domain protein & Os08g44850 & 1.2 & C2 domain containing protein & MCL5451 \\
\hline \multicolumn{7}{|c|}{ Transcription factors } \\
\hline ZM2G347043 & 3.4 & NAC49; ZmSNAC1 & Os03g60080 & 3.4 & SNAC1, stress-responsive NAC 1 & MCL15794 \\
\hline ZM2G069146 & 4.2 & $\begin{array}{l}\text { dehydration-responsive } \\
\text { element-binding protein }\end{array}$ & Os09g35030 & 3.5 & OsDREB1A & MCL12934 \\
\hline ZM2G061487 & 2.3 & DRE binding factor 1 & Os08g31580 & 1.4 & $\begin{array}{l}\text { ERF, ethylene-responsive } \\
\text { transcription factor }\end{array}$ & MCL17488 \\
\hline ZM2G174347 & 1.4 & ERF & Os05g41780 & 1.0 & AP2 domain containing protein & MCL5811 \\
\hline ZM2G068967 & 1.9 & ERF & Os04g52090 & 1.4 & OsAP2-39 & MCL12147 \\
\hline ZM2G438202 & 2.0 & ERF & & & & MCL12147 \\
\hline ZM2G474326 & 2.0 & ERF & Os01g54890 & 2.7 & OsERF922 & MCL13082 \\
\hline ZM2G093270 & 1.4 & PLATZ transcription factor & Os10g42410 & 3.7 & zinc-binding protein & MCL17475 \\
\hline ZM2G101058 & 1.3 & GATA28 & Os10g40810 & 0.7 & GATA zinc finger domain protein & MCL1807 \\
\hline ZM2G361210 & 6.7 & $\mathrm{C} 2 \mathrm{H} 2$ Zinc finger protein ZAT11 & Os03g60570 & 5.7 & ZFP15, C2H2 zinc finger protein & MCL13769 \\
\hline ZM2G061626 & 5.3 & $\mathrm{C} 2 \mathrm{H} 2$ zinc finger protein & Os03g60560 & 7.5 & ZFP182, C2H2 zinc finger protein & MCL13770 \\
\hline ZM2G158328 & 3.3 & WRKY40 & Os01g60600 & 2.0 & WRKY108 & MCL17062 \\
\hline \multicolumn{7}{|c|}{ Phytohormone signaling } \\
\hline ZM2G014392 & 4.6 & $\begin{array}{l}\text { vp14, 9-cis-epoxycarotenoid } \\
\text { dioxygenase }\end{array}$ & Os03g44380 & 3.4 & $\begin{array}{l}\text { OsNCED3, 9-cis-epoxycarotenoid } \\
\text { dioxygenase }\end{array}$ & MCL9668 \\
\hline ZM2G427451 & 0.8 & AlR12 & Os08g41290 & 0.7 & $\begin{array}{l}\text { AIR12, auxin-induced in root } \\
\text { cultures }\end{array}$ & MCL9576 \\
\hline ZM2G036351 & 5.3 & ZIM transcription factor & Os03g08330 & 3.5 & $\begin{array}{l}\text { OsJAZ10, ZIM domain containing } \\
\text { protein }\end{array}$ & MCL14008 \\
\hline ZM2G173630 & 1.6 & GID1 (GA-insensitive dwarf) & Os05g33730 & -0.7 & gibberellin receptor GID1L2 & MCL4519 \\
\hline ZM2G033846 & 3.3 & caltractin & Os03g19720 & 3.7 & EF hand family protein & MCL5182 \\
\hline ZM2G312661 & 1.8 & Calmodulin & Os03g21380 & 1.5 & $\begin{array}{l}\text { OsCML27, Calmodulin-related } \\
\text { protein }\end{array}$ & MCL16352 \\
\hline \multicolumn{7}{|l|}{ Cell wall } \\
\hline ZM2G110558 & 1.1 & UDP-glucuronate 4-epimerase & Os02g54890 & 0.9 & UDP-glucuronate 4-epimerase & MCL7320 \\
\hline ZM2G042179 & 0.8 & UDP-glucuronate 4-epimerase & & & & MCL7320 \\
\hline ZM2G015886 & 0.7 & Cellulose synthase D4 & Os12g36890 & 0.9 & $\begin{array}{l}\text { CSLD4, cellulose synthase-like } \\
\text { family } D \text {, }\end{array}$ & MCL85 \\
\hline ZM2G135743 & 1.0 & $\begin{array}{l}\text { glycogenin-like starch initiation } \\
\text { protein }\end{array}$ & Os01g65780 & -0.9 & glycosyl transferase & MCL1732 \\
\hline \multicolumn{7}{|c|}{ Posttranslational modification } \\
\hline ZM2G172230 & 2.4 & $\begin{array}{l}\text { CaseinoLytic Protease ClpD, } \\
\text { chloroplastic }\end{array}$ & Os02g32520 & 1.3 & $\begin{array}{l}\text { OsClpD1, early responsive to } \\
\text { dehydration ERD1 }\end{array}$ & MCL2599 \\
\hline ZM2G328785 & 3.5 & ZmPK1, receptor protein kinase & Os11g03820 & -1.3 & $\begin{array}{l}\text { S-locus-like receptor protein } \\
\text { kinase }\end{array}$ & MCL8097 \\
\hline ZM2G359986 & 1.8 & $\begin{array}{l}\text { Wall-associated receptor } \\
\text { kinase-like } 20\end{array}$ & Os05g25390 & 2.4 & tyrosine protein kinase & MCL7431 \\
\hline ZM2G443509 & -0.7 & protein phosphatase $2 \mathrm{C}$ & Os04g33080 & -1.2 & protein phosphatase $2 \mathrm{C}$ & MCL2430 \\
\hline
\end{tabular}

The DEGs identified in both previous reports $[39,40]$ are in bold, and the DEGs underlined are also Cd-responsive in previous report [19] 


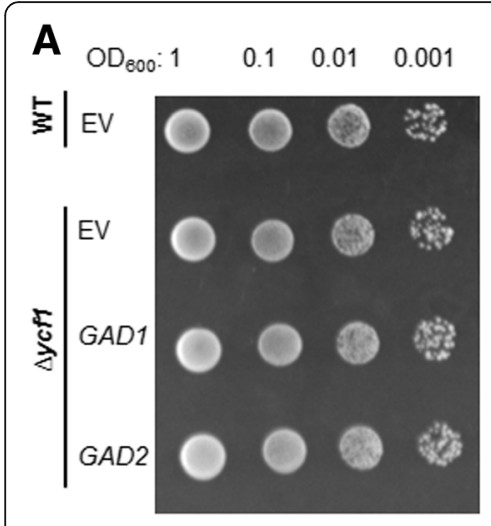

Control

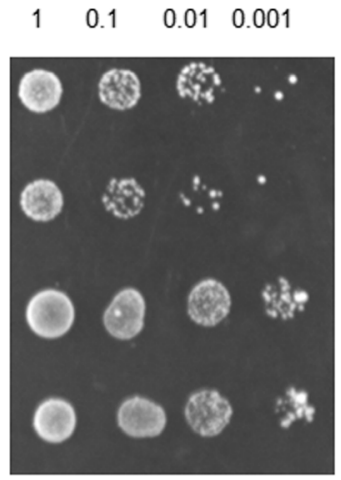

Cd: $40 \mu \mathrm{M}$

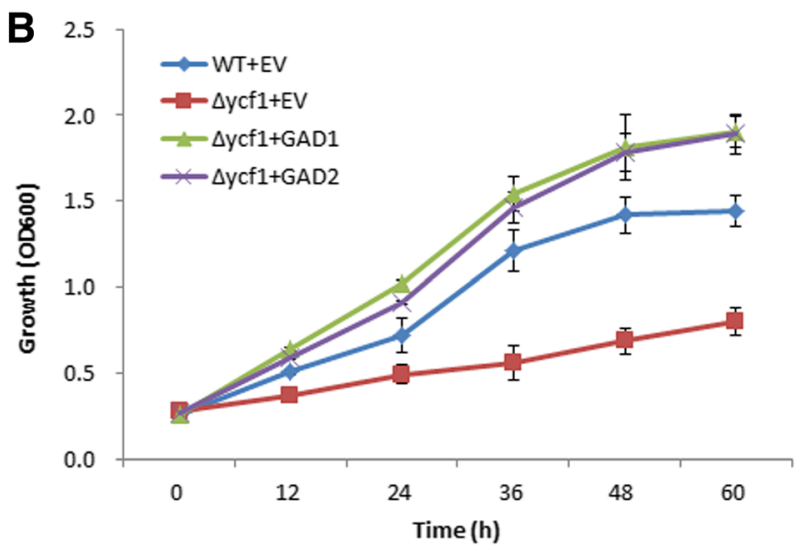

B 2.5

Fig. 2 Maize $Z m G A D 1$ and $Z m G A D 2$ conferred Cd tolerance in yeast. a The survival test of yeast strains transformed with ZmGADs on SG-Ura agar medium supplemented with $40 \mu \mathrm{M} \mathrm{CdCl}_{2}$ in the presence of $2 \%$ galactose. The photographs were taken 3 days post incubation, with three independent experiments. b Time-dependent growth curves of yeast transformed with $\mathrm{ZmGADs}$ in SG-Ura liquid medium with $30 \mu \mathrm{M} C \mathrm{CCl} \mathrm{I}_{2}$ and $2 \%$ galactose. The growth of the yeast cells was monitored at $\mathrm{OD}_{600}$. Data are presented as means $\pm \mathrm{SE}(n=3)$. Error bars indicate SE of three independent biological experiments. Statistical analysis was performed using SPSS20.0 software were significantly reduced than those on leaves expressing EV after Cd treatment (Fig. 3b).

These results, confirmed in yeast and tobacco leaves through ectopic expression, suggest that maize GADs confer Cd tolerance.

\section{Discussion}

Coordinated expression of transporters orthologs indicate their conserved function in $\mathrm{Cd}$-stressed maize and rice.

To further explore the common regulatory mechanisms in maize and rice under Cd stress, we compared Cd-regulated 5166 maize DEGs with their 2567 counterparts in rice (Additional file 3: Table S3, Additional file 5: Table S5). As anticipated, the majority of the orthologous DEGs in maize and rice showed coordinated expression pattern after Cd treatment. Notably, 994 out of 1074 maize DEGs with rice counterparts were not stated as being Cd-responsive genes previously (Table 2, Additional file 6: Table S6).

Among the co-modulated transporters in Cd-treated maize and rice roots, it is noticeable that $\mathrm{Cd}$-responsive HIPPs were categorized into 3 groups of co-upregulated orthologs (Table 2). HIPP metallochaperones, containing a metal binding domain, play a pivotal role in heavy metal homeostasis and detoxification, especially in $\mathrm{Cd}$
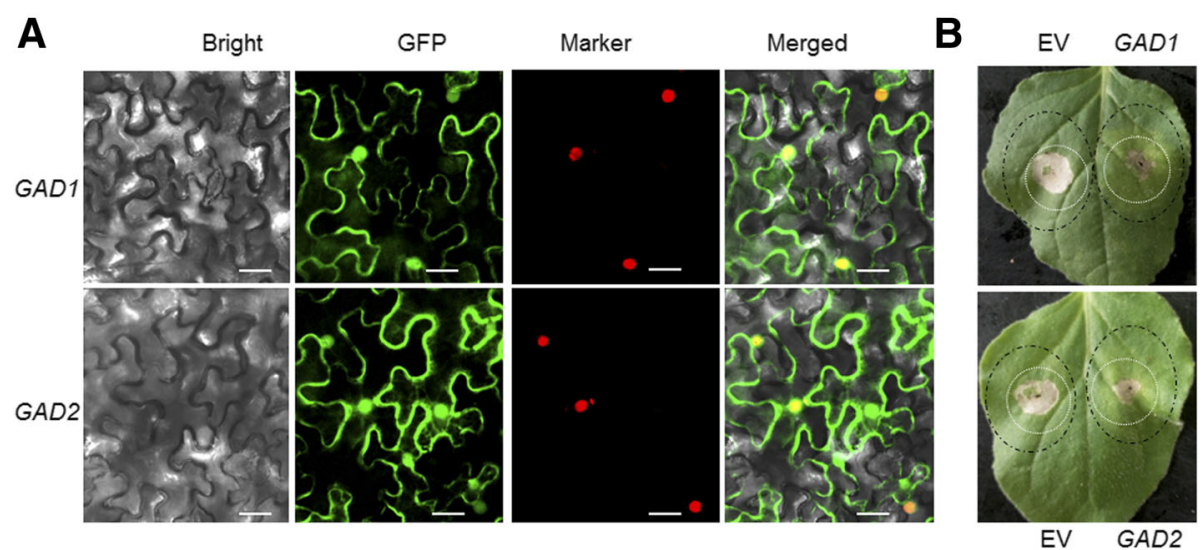

Fig. 3 Transient expression of maize ZmGAD1 and ZmGAD2 in tobacco leaves led to increased tolerance to Cd. a Nuclear localization of GFPtagged ZmGAD1 and ZmGAD2 fusion proteins in N. benthamiana. Epidermal cells of $N$. benthamiana leaves transiently expressing GFP fusion proteins were observed using confocal microscopy at 4 days post agro-infiltration. RFP-H2A, localized in the nucleus, was used to indicate the nuclei [36]. Scale bars $=50 \mu \mathrm{m}$. b Lesions were photographed at 4 days post Cd treatment on EV transformed control regions (left half-leaf) and regions transient expressing ZmGADs (the right part). Cd-infiltrated areas are indicated by the internal white circles, whereas agro-infiltrated areas are indicated by the larger black circles 
tolerance [41-43]. Overexpression of Arabidopsis AtHIPPO6 [44] or AtHIPP26 [45] conferred Cd tolerance to transgenic plants, however, the triple knockout mutant hipp20/21/22 was more sensitive to Cd [43]. Interestingly, AtHIPPO6 and AtHIPP26 were distributed to two $\mathrm{Cd}$ co-modulated orthologous groups containing ZmHIPP35 and ZmHIPP27, respectively.

The other notable orthologous transporter cluster is MCL2, which was exclusively composed of Cd-upregulated ABCGs/PDRs (Table 2). Among them, ABCG36/OsPDR9 is reported induced rapidly and markedly in rice roots by $\mathrm{Cd}$ and $\mathrm{Zn}$ [46]. In rice, the Cd-inducible OsABCG43/ PDR5 is likely to sequester $\mathrm{Cd}$ at the subcellular level [47], and its Arabidopsis homologs, AtPDR12 and AtPDR8, are all involved in heavy metal resistance, and the Cd-inducible AtPDR8 can confer $\mathrm{Cd}$ resistance as an extrusion pump [48]. Comparative transcriptomic analysis in two Solanum species with differential $\mathrm{Cd}$ accumulation suggests that the Solanum PDR2, which most closely related Arabidopsis gene is AtPDR12, may be involved in heavy metal resistance and transmembrane transport [6]. It is interesting to note that AtPDR12 and AtPDR8 also are members of the orthologs cluster MCL2.

Yet another interesting orthologs are ZIP transporters, which were synergistically downregulated by $\mathrm{Cd}$ stress, although they are dispersed in 4 orthologs clusters (Table 2). In plants, Cd is taken up and transported across plant membranes mainly by hijacking transporters for essential metals such as Zn, Fe, and Mn. For instance, members of the ZIP family are capable of transporting a variety of divalent cations such as $\mathrm{Cd}, \mathrm{Mn}, \mathrm{Fe}$ and $\mathrm{Zn}$ ions $[49,50]$. Even in $\mathrm{Zn} / \mathrm{Cd}$-hyperaccumulators, $\mathrm{Cd}$ absorption from the soil is thought to occur mainly via ZIP family transporters [1]. For maize ZIP genes, they are suggested to be responsible for the uptake and translocation of $\mathrm{Zn}$ or $\mathrm{Fe}$ and involved in detoxification and storage of metals in plant cells [51].

Collectively, the similar expression pattern of these transporter orthologs in Cd-treated maize and rice roots could be as a consequence of the conserved function of orthologous genes. However, for the 3 types of transporters discussed above, only one ABCG (ZM2G391815) was mentioned as being Cd-responsive previously [19]. Therefore, further research is needed to determine the functional identity and precise roles of these promising $\mathrm{Cd}$-modulated transporters in $\mathrm{Cd}$ tolerance.

\section{Conserved function of maize paralogs derived from gene tandem duplication}

Gene duplication drives the evolution of novel functions, and plant genes involved in transcriptional regulation, signal transduction, and stress response tend to have paralogs [52-54]. Consistent with this hypothesis, the tandem gene duplication of heavy metal ATPase HMA4, which contributed to $\mathrm{Zn} / \mathrm{Cd}$ hyperaccumulation in Arabidopsis halleri, was also occurred in another hyperaccumulator Noccaea caerulescens $[55,56]$.

In the current study, it was interesting to observe that there were several blocks of paralogs co-modulated by $\mathrm{Cd}$ stress (Table 1). For instance, the members of two blocks of GLPs on chromosome 4 are independently sorted in tandem (Table 1). Importantly, tandem duplications appear to play an important role in expansion of the GLP family in rice and Arabidopsis [57]. It is known that GLPs can function as a cofactor for reinforcement of the cell wall through the production of $\mathrm{H}_{2} \mathrm{O}_{2}$ due to their SOD activity (e.g. OsGLP1, OsGLP2-1) [57-60]. Although no study has reported on the relationship between GLPs and the heavy metal tolerance in plant, the synchronized upregulation of GLP paralogs in Cd-treated maize roots is probably associated with their role in orchestrating $\mathrm{Cd}$ response.

Another tandem paralogs cluster is composed of two PALs on chromosome 5 (Table 1). Akin to this, 4 PAL genes were reported to be clustered on the same chromosome 2 [61]. PAL is the entry point enzyme directing the flow of reduced carbon to the various branches of phenylpropanoid metabolism, which products include soluble phenolics, flavonoids and the cell wall structural component lignin, all having diverse functions in plant development and response to abiotic and biotic challenges [61-63]. Furthermore, the phenylpropanoid pathway metabolites of yellow lupine roots could promote $\mathrm{Pb}$ stress tolerance [64].

Additionally, two patatin-like storage proteins are Cd-regulated tandem paralogs on chromosome 2, while the other two are reverse tandem paralogs on chromosome 1 , and the latter two were also identified to be Cd-responsive in one previous report [19] (Table 1). It has been documented that patatin-like genes are involved in stress responses, hormone signaling, and development [65-67].

Yet another interesting tandem Cd-responsive paralogs are genes responsible for JA biosynthesis, since both 2 LOXs and 2 AOSs responsible for forming intermediate compounds in JA biosynthesis process are $\mathrm{Cd}$-inducible and clustered on chromosome 1 . The products of LOX enter oxylipin biosynthetic pathways where JAs are formed through the AOS branch [67-69]. JAs play multifunctional roles in regulation of tolerance against different environmental stresses including heavy metals $[68,70]$. In heavy metal-treated plants, the concentration of JA was often elevated, thereby promoting the expression of genes involved in signaling pathways (such as ABA, ROS) and stress responses (e.g. transcription factors, antioxidant system, GSH biosynthesis) to alleviate heavy metal-induced toxicity in plants [70]. Among the 80 universal Cd-responsive DEGs, both ZmOPR2 and ZmOPR5 in cluster MCL166 (Table 1) were also significantly upregulated in both maize genotypes [19]. The 
synchronized expression patterns of OPRs and JA-responsive TFs genes have indicated that the JA signaling pathway is one of the crucial elements in the plant response to Cd stress [24, 71].

Taken together, several blocks of paralogs, such as GLPs, PALs and those involved in JA biosynthesis, displayed consistent co-expression pattern under Cd stress (Table 1 ). In this context, we proposed that these Cd-responsive paralogs contributed to Cd-tolerance, and their function might be conserved post gene tandem duplication.

\section{Common stress-responsive maize genes}

In obvious manner, the regulation in hormone synthesis has been observed during heavy metal stress. It was well documented that the increased expression of NCED, the key enzyme for the synthesis of stress phytohormone ABA, was positively related to various stress tolerance [72], thus it was not surprising that the Cd-inducible NCED (ZM2G014392) is also one common stress-responsive maize gene (Table 3), which was identified in both two previous transcriptomic studies focusing on abiotic stresses responses [39, 40], but not mentioned as being Cd-responsive gene previously [19].

$\mathrm{ABA}$ and JA act synergistically in response to stress, and ethylene-responsive transcription factors (ERFs) are interesting targets for both JA-ABA interactions and ethylene [73]. In this investigation, the simultaneous upregulation of genes involved in biosynthesis of $\mathrm{ABA}$ (NCED), JA (LOX, AOS, AOC and OPR), and ethylene signaling (ERFs) suggests that these multiple-stress mediators coordinate the stress response in maize roots exposed to $\mathrm{Cd}$ (Table 1, Table 3), thus constitute a recurring theme of phytohormone crosstalk.

It was striking that the aforementioned metallochaperone ZmHIPP27 is one common stress-responsive gene (Table 3), and this is reminiscent of its rice ortholog OsHIPP42, which was one of the HIPPs associated with the response to a wide range of abiotic stresses including heavy metal (As, $\mathrm{Cd}, \mathrm{Cr}$, and $\mathrm{Pb}$ ) toxicity [74]. HIPPs are unique to vascular plants and function in heavy metal homeostasis and regulating the transcriptional response to abiotic stresses and pathogens [41, 75]. Abiotic stresses inducible Arabidopsis AtHIPP26 interacts via its HMAD with the drought stress related zinc finger transcription factor ATHB29 [76]. There is substantial evidence that HIPPs can have a role in Cd-detoxification, possibly by binding $\mathrm{Cd}$ [43]. Moreover, the plants overexpressing AtHIPP26 were more tolerant to $\mathrm{Cd}$ treatment than wild type [45]. Therefore, this common stress-responsive ZmHIPP27, the ortholog of abiotic stresses inducible AtHIPP26 and OsHIPP42, together with the latter rice ortholog, provide a new avenue to further investigate the molecular mechanism beneath the $\mathrm{Cd}$ stress response in crop plants.
Of particular interest is the rice SNAC1, which overexpression improves both drought and salt tolerance in rice and cotton [77, 78], thus it has been alluded to be common stress-responsive [22, 77]. In the present study, SNAC1 and its ortholog in maize were identified to be common stress-responsive as well as Cd-inducible genes (Table 3). ZmSNAC1 has been described as a stress-responsive factor acting in positive modulation of abiotic stress tolerance, and ZmSNAC1 confers enhanced tolerance to dehydration in transgenic Arabidopsis [79].

These results collectively suggest that these orthologous genes, simultaneously modulated in maize and rice roots exposed to $\mathrm{Cd}$ treatment are also common stressresponsive genes in both species. However, the majority of the 30 common stress-responsive genes except ClpD and $\mathrm{ZmPK} 1$ were not mentioned in previous $\mathrm{Cd}$-stressed maize transcriptomic study (Table 3) [19]. Thus, the present transcriptomic analysis provides novel valuable information about the conserved $\mathrm{Cd}$ response from the viewpoint of common stress-responsive genes, such as ZmHIPP27 and SNAC1, which may facilitate further investigations on the $\mathrm{Cd}$-tolerance mechanisms.

\section{The key enzyme for GABA biosynthesis GAD contributed to $c d$ tolerance}

GABA-regulated processes are thought to include developmental regulation, stress tolerance, carbon:nitrogen balance, and long-distance transport [80]. The rapid accumulation of GABA during biotic and abiotic stresses is well documented [81-84]. For instance, heavy metals (e.g. $\mathrm{Cu}, \mathrm{Zn}$ and $\mathrm{Cr}$ ) stimulated the accumulation of GABA [85, 86]. GABA works in harmony with phytohormones and the regulation of phytohormones by exogenous GABA could play a key role in combating plant stress [87]. These collectively indicate GABA as one common stress signal [82]. Therefore, exogenous GABA enhances plant resistance to some stresses. For instance, GABA treatment might protect rice plants against the deleterious effects of ammonium toxicity [88]. GABA also imparts partial protection from salt stress injury to maize seedlings [89].

Further investigations suggested that exogenous application of GABA resulted in a significant increase in endogenous GABA concentration, and this accumulation of GABA was associated with the activity of GAD, the key enzyme catalyzing the decarboxylation of glutamate to GABA [82, 84, 90-92].

Overexpressing SIGAD3 in tomato fruits led to an increase in GABA levels at the red-ripe stage [92]. Rice plants overexpressing OsGAD gene were able to accumulate GABA under short-term salinity [93]. Several GAD genes were upregulated at the mRNA level and this is subsequently reflected in an increase in GABA at the metabolite level in tobacco under drought stress [94]. 
In the current study, overexpression of maize ZmGAD1 and ZmGAD2 in Cd-sensitive yeast and tobacco leaves in planta all enhanced $\mathrm{Cd}$ tolerance of the host cells (Figs. 2, 3). These findings implicated that GADs participate in the accumulation of GABA, which contribute to stress acclimation or alleviation.

\section{Conclusions}

In summary, the ortholog analysis of Cd-treated maize and rice transcriptomes uncovered 880 orthologs groups, and the highlight was the discovery of $\mathrm{Cd}$ co-modulated orthologs in this two cereal crops. Further comparative investigation revealed that $\sim 30$ maize Cd-responsive genes with rice counterparts were also common stress-responsive genes such as heavy metal-associated domain (HMAD) isoprenylated protein ZmHIPP27, stress-responsive transcription factor ZmSNAC1, and vp14 (one NCED for ABA biosynthesis). These collectively suggest that the network underlying $\mathrm{Cd}$ stress responses and tolerance, which different plant species have developed to adapt to other stresses, could assist plants to acclimate to diverse stresses. Importantly, the orthologs of GAD, the key enzyme for GABA synthesis, were concomitantly upregulated in maize and rice roots exposed to $\mathrm{Cd}$ treatment. Moreover, maize GADs confer $\mathrm{Cd}$ tolerance in yeast and tobacco leaves in planta via heterologous expression. Notably, the aforementioned several promising Cd-upregulated genes (e.g. ZmHIPP27, $Z m S N A C 1, v p 14$ and $Z m G A D s$ ) with rice counterparts were identified to be novel Cd-responsive genes in maize. This study extends the understanding of the common molecular mechanisms of plant roots response to $\mathrm{Cd}$ and other abiotic stresses, and will be useful for deciphering major candidate genes for improving $\mathrm{Cd}$ tolerance in cereal plants.

\section{Additional files}

Additional file 1: Table S1. RNAseq information of maize roots under Cd stress. (XLSX $9 \mathrm{~kb}$ )

Additional file 2: Table S2. Primers used for quantitative RT-PCR and cloning maize GADs. (XLSX $10 \mathrm{~kb}$ )

Additional file 3: Table S3. Cd-responsive 5166 DEGs in maize roots post Cd treatment. (XLSX $513 \mathrm{~kb}$ )

Additional file 4: Table S4. Quantitative RT-PCR of 10 random selected DEGs expression in maize roots exposed to Cd. (XLSX $10 \mathrm{~kb}$ )

Additional file 5: Table S5. Cd-responsive 2567 DEGs in rice roots post Cd treatment. (XLSX $268 \mathrm{~kb}$ )

Additional file 6: Table S6. Eight hundred eighty plant orthologous groups composed of $\mathrm{Cd}$-responsive orthologs in maize and rice. (XLSX $78 \mathrm{~kb}$ )

Additional file 7: Figure S1. Global view of Cd-responsive maize orthologs with rice counterparts in metabolic pathways. For the 1074 maize DEGs with rice orthologs, 471 data points were visible on the metabolic pathways (Arabidopsis seed-Molecular Networks) using MapMan software. The colored boxes indicate the Log2 ratio of Cd1h/ck1h. (PDF $1258 \mathrm{~kb}$ )

\section{Abbreviations}

ABC: ATP-binding cassette; AOS: Allene oxidase synthase; ClpD: Chloroplastic caseinolytic protease; DEG: Differentially expressed gene; ERF: EthyleneResponse Factor; GABA: $\gamma$-aminobutyric acid; GAD: Glutamate decarboxylase; GLP: Germin-like protein; HIPP: HMAD isoprenylated plant protein; HMA: Hheavy metal ATPase; HMAD: Heavy metal associated domain containing protein; HSF: Heat shock transcription factor; JA: Jasmonic acid; LOX: Lipoxygenase; MATE: Multidrug and toxic compound extrusion; NCED: 9-cis-epoxycarotenoid dioxygenase; OPR: 12-oxo-phytodienoic acid reductase; PAL: Phenylalanine ammonia-lyase; PDR: Pleiotropic drug resistance; SNAC1: Stress-responsive NAC 1; ZFP: Zinc finger protein; ZIP: ZRT- and IRT-like protein

\section{Acknowledgements}

We are grateful to Jianbing Yan (Huazhong Agricultural University) for sharing the seeds of B73 maize.

\section{Funding}

This work was supported by research grants from the National Natural Science Foundation of China (No. 31271421). None of the members of this funder participated in the study design, data collection and analysis, or preparation of the manuscript.

\section{Availability of data and materials}

The datasets supporting the conclusions of this article are included within the article and its additional files. The sequence data are available in the NCBI Sequence Read Archive under the accession number of SRP053169 for rice and SRP115510 for maize.

\section{Authors' contributions}

MT, YC and MJ conceived and designed the experiments. HY, LL and DZ performed the experiments. DC and MT analyzed the data. MT, DC, YC and MJ supervised manuscript discussion and writing. All authors discussed the results and commented on the manuscript. All authors read and approved the final manuscript.

\section{Ethics approval and consent to participate}

Not applicable. The maize B73 seeds used in this study were kindly provided by Jianbing Yan from Huazhong Agricultural University, and the samples collected from B73 seedlings were for research use only.

\section{Consent for publication}

Not applicable.

\section{Competing interests}

The authors declare that they have no competing interests.

\section{Publisher's Note}

Springer Nature remains neutral with regard to jurisdictional claims in published maps and institutional affiliations.

Received: 29 July 2018 Accepted: 21 September 2018 Published online: 26 September 2018

\section{References}

1. Clemens S, Aarts MG, Thomine S, Verbruggen N. Plant science: the key to preventing slow cadmium poisoning. Trends Plant Sci. 2013;18(2):92-9.

2. Sasaki A, Yamaji N, Ma JF. Overexpression of OsHMA3 enhances cd tolerance and expression of Zn transporter genes in rice. J Exp Bot. 2014; 65(20):6013-21.

3. Yang M, Zhang Y, Zhang L, Hu J, Zhang X, Lu K, Dong H, Wang D, Zhao FJ, Huang CF, et al. OsNRAMP5 contributes to manganese translocation and distribution in rice shoots. J Exp Bot. 2014;65(17):4849-61.

4. Brunetti P, Zanella L, De Paolis A, Di Litta D, Cecchetti V, Falasca G, Barbieri M, Altamura MM, Costantino P, Cardarelli M. Cadmium-inducible expression of the ABC-type transporter AtABCC3 increases phytochelatin-mediated cadmium tolerance in Arabidopsis. J Exp Bot. 2015;66(13):3815-29.

5. Yamaguchi N, Ishikawa S, Abe T, Baba K, Arao T, Terada Y. Role of the node in controlling traffic of cadmium, zinc, and manganese in rice. J Exp Bot. 2012;63(7):2729-37. 
6. Xu J, Sun J, Du L, Liu X. Comparative transcriptome analysis of cadmium responses in Solanum nigrum and Solanum torvum. New Phytol. 2012;196(1):110-24.

7. Yu R, Li D, Du X, Xia S, Liu C, Shi G. Comparative transcriptome analysis reveals key cadmium transport-related genes in roots of two pak choi (Brassica rapa L. ssp. chinensis) cultivars. BMC Genomics. 2017;18(1):587.

8. Zhao X, Luo L, Cao Y, Liu Y, Li Y, Wu W, Lan Y, Jiang Y, Gao S, Zhang Z, et al. Genome-wide association analysis and QTL mapping reveal the genetic control of cadmium accumulation in maize leaf. BMC Genomics. 2018;19(1):91.

9. Xu L, Wang Y, Zhai L, Xu Y, Wang L, Zhu X, Gong Y, Yu R, Limera C, Liu L. Genome-wide identification and characterization of cadmium-responsive microRNAs and their target genes in radish (Raphanus sativus L.) roots. J Exp Bot. 2013;64(14):4271-87.

10. Gu CS, Liu LQ, Deng YM, Zhang YX, Wang ZQ, Yuan HY, Huang SZ. De novo characterization of the Iris lactea var. chinensis transcriptome and an analysis of genes under cadmium or lead exposure. Ecotox Environ Safe. 2017;144:507-13.

11. Han X, Yin H, Song X, Zhang Y, Liu M, Sang J, Jiang J, Li J, Zhuo R. Integration of small RNAs, degradome and transcriptome sequencing in hyperaccumulator Sedum alfredii uncovers a complex regulatory network and provides insights into cadmium phytoremediation. Plant Biotechnol J. 2016;14(6):1470-83.

12. Yang J, Li K, Zheng W, Zhang H, Cao X, Lan Y, Yang C, Li C. Characterization of early transcriptional responses to cadmium in the root and leaf of $\mathrm{cd}$ resistant Salix matsudana Koidz. BMC Genomics. 2015;16:705.

13. Wang $Y$, Wang $X$, Wang C, Peng F, Wang R, Xiao X, Zeng J, Kang H, Fan X, Sha $L$, et al. Transcriptomic profiles reveal the interactions of $c d / Z n$ in dwarf polish wheat (Triticum polonicum L.) roots. Front Physiol. 2017;8:168.

14. Feng J, Jia W, Lv S, Bao H, Miao F, Zhang X, Wang J, Li J, Li D, Zhu C, et al. Comparative transcriptome combined with morpho-physiological analyses revealed key factors for differential cadmium accumulation in two contrasting sweet sorghum genotypes. Plant Biotechnol J. 2018;16(2):558-71.

15. Chen L, Shi S, Jiang N, Khanzada H, Wassan GM, Zhu C, Peng X, Xu J, Chen $Y, Y u Q$, et al. Genome-wide analysis of long non-coding RNAs affecting roots development at an early stage in the rice response to cadmium stress. BMC Genomics. 2018;19(1):460

16. Oono Y, Yazawa T, Kanamori H, Sasaki H, Mori S, Matsumoto T. Genomewide analysis of rice cis-natural antisense transcription under cadmium exposure using strand-specific RNA-Seq. BMC Genomics. 2017;18(1):761.

17. Cao F, Chen F, Sun H, Zhang G, Chen ZH, Wu F. Genome-wide transcriptome and functional analysis of two contrasting genotypes reveals key genes for cadmium tolerance in barley. BMC Genomics. 2014;15:611.

18. Yue R, Lu C, Qi J, Han X, Yan S, Guo S, Liu L, Fu X, Chen N, Yin H, et al. Transcriptome analysis of cadmium-treated roots in maize (Zea mays L.). Front Plant Sci. 2016;7:1298.

19. Peng H, He X, Gao J, Ma H, Zhang Z, Shen Y, Pan G, Lin H. Transcriptomic changes during maize roots development responsive to cadmium (cd) pollution using comparative RNAseq-based approach. Biochem Bioph Res Commun. 2015;464(4):1040-7.

20. He F, Liu Q, Zheng L, Cui Y, Shen Z. RNA-Seq analysis of rice roots reveals the involvement of post-transcriptional regulation in response to cadmium stress. Front Plant Sci. 2015;6:1136.

21. Kawahara Y, Oono Y, Wakimoto H, Ogata J, Kanamori H, Sasaki H, Mori S, Matsumoto T, Itoh T. TENOR: database for comprehensive mRNA-Seq experiments in rice. Plant Cell physiol. 2016;57(1):e7.

22. Oono Y, Yazawa T, Kawahara Y, Kanamori H, Kobayashi F, Sasaki H, Mori S, Wu J, Handa H, Itoh T, et al. Genome-wide transcriptome analysis reveals that cadmium stress signaling controls the expression of genes in drought stress signal pathways in rice. PLoS One. 2014;9(5):e96946.

23. Tang M, Mao D, Xu L, Li D, Song S, Chen C. Integrated analysis of miRNA and $\mathrm{mRNA}$ expression profiles in response to $\mathrm{cd}$ exposure in rice seedlings. BMC Genomics. 2014;15:835

24. Tan M, Cheng D, Yang Y, Zhang G, Qin M, Chen J, Chen Y, Jiang M. Coexpression network analysis of the transcriptomes of rice roots exposed to various cadmium stresses reveals universal cadmium-responsive genes. BMC Plant Biol. 2017:17(1):194

25. Trapnell C, Roberts A, Goff L, Pertea G, Kim D, Kelley DR, Pimentel H, Salzberg SL, Rinn JL, Pachter L. Differential gene and transcript expression analysis of RNA-seq experiments with TopHat and cufflinks. Nature Protoc. 2012;7(3):562-78.

26. Usadel B, Poree F, Nagel A, Lohse M, Czedik-Eysenberg A, Stitt M. A guide to using MapMan to visualize and compare Omics data in plants: a case study in the crop species, maize. Plant Cell Environ. 2009;32(9):1211-29.
27. Yan J, Wang P, Yang M, Lian X, Tang Z, Huang CF, Salt DE, Zhao FJ. A lossof-function allele of OsHMA3 associated with high cadmium accumulation in shoots and grain of japonica rice cultivars. Plant Cell Environ. 2016;39(9): 1941-54.

28. Chen X, Li J, Wang L, Ma G, Zhang W. A mutagenic study identifying critical residues for the structure and function of rice manganese transporter OsMTP8.1. Sci Rep. 2016;6:32073.

29. Kunihiro S, Saito T, Matsuda T, Inoue M, Kuramata M, Taguchi-Shiobara F, Youssefian S, Berberich T, Kusano T. Rice DEP1, encoding a highly cysteinerich $\mathrm{G}$ protein gamma subunit, confers cadmium tolerance on yeast cells and plants. J Exp Bot. 2013;64(14):4517-27.

30. Chen Y, Chen C, Tan Z, Liu J, Zhuang L, Yang Z, Huang B. Functional identification and characterization of genes cloned from halophyte Seashore paspalum conferring salinity and cadmium tolerance. Front Plant Sci. 2016;7:102.

31. Shim D, Hwang JU, Lee J, Lee S, Choi Y, An G, Martinoia E, Lee Y. Orthologs of the class A4 heat shock transcription factor HsfA4a confer cadmium tolerance in wheat and rice. Plant Cell. 2009;21(12):4031-43.

32. Kong L, Qiu X, Kang J, Wang Y, Chen H, Huang J, Qiu M, Zhao Y, Kong G, Ma Z, et al. A phytophthora effector manipulates host histone acetylation and reprograms defense gene expression to promote infection. Curr Biol. 2017;27(7):981-91.

33. Lin T, Yang W, Lu W, Wang Y, Qi X. Transcription factors PvERF15 and PVMTF-1 form a cadmium stress transcriptional pathway. Plant Physiol. 2017; 173(3):1565-73

34. Jing $M$, Guo B, Li H, Yang B, Wang H, Kong G, Zhao Y, Xu H, Wang Y, Ye W, et al. A Phytophthora sojae effector suppresses endoplasmic reticulum stress-mediated immunity by stabilizing plant binding immunoglobulin proteins. Nat Commun. 2016;7:11685.

35. Song T, Ma Z, Shen D, Li Q, Li W, Su L, Ye T, Zhang M, Wang Y, Dou D. An oomycete CRN effector reprograms expression of plant HSP genes by targeting their promoters. PLoS Pathog. 2015;11(12):e1005348.

36. Ochiai $H$, Sugawara $T$, Yamamoto $T$. Simultaneous live imaging of the transcription and nuclear position of specific genes. Nucleic Acids Res. 2015; 43(19):e127

37. Wang L, Czedik-Eysenberg A, Mertz RA, Si Y, Tohge T, Nunes-Nesi A, Arrivault S, Dedow LK, Bryant DW, Zhou W, et al. Comparative analyses of $C_{4}$ and $C_{3}$ photosynthesis in developing leaves of maize and rice. Nature Biotechnol. 2014;32(11):1158-65.

38. Ouyang S, Zhu W, Hamilton J, Lin H, Campbell M, Childs K, Thibaud-Nissen F, Malek RL, Lee $Y$, Zheng L, et al. The TIGR Rice genome annotation resource: improvements and new features. Nucleic Acids Res. 2007; 35(Database):D883-7.

39. Shan $X$, Li Y, Jiang Y, Jiang Z, Hao W, Yuan Y. Transcriptome profile analysis of maize seedlings in response to high-salinity, drought and cold stresses by deep sequencing. Plant Mol Biol Rep. 2013;31(6):1485-91.

40. Li P, Cao W, Fang H, Xu S, Yin S, Zhang Y, Lin D, Wang J, Chen Y, Xu C, et al Transcriptomic profiling of the maize (Zea mays I.) leaf response to abiotic stresses at the seedling stage. Front Plant Sci. 2017;8:290.

41. de Abreu-Neto JB, Turchetto-Zolet AC, de Oliveira LF, Zanettini MH, MargisPinheiro M. Heavy metal-associated isoprenylated plant protein (HIPP): characterization of a family of proteins exclusive to plants. FEBS J. 2013; 280(7):1604-16.

42. Imran QM, Falak N, Hussain A, Mun BG, Sharma A, Lee SU, Kim KM, Yun BW. Nitric oxide responsive heavy metal-associated gene AtHMAD1 contributes to development and disease resistance in Arabidopsis thaliana. Front Plant Sci. 2016;7:1712

43. Tehseen M, Cairns N, Sherson S, Cobbett CS. Metallochaperone-like genes in Arabidopsis thaliana. Metallomics. 2010;2(8):556-64.

44. Suzuki N, Yamaguchi Y, Koizumi N, Sano H. Functional characterization of a heavy metal binding protein Cdl19 from Arabidopsis. Plant J. 2002;32(2): 165-73.

45. Gao W, Xiao S, Li HY, Tsao SW, Chye ML. Arabidopsis thaliana acyl-CoAbinding protein ACBP2 interacts with heavy-metal-binding farnesylated protein AtFP6. New Phytol. 2009;181(1):89-102.

46. Moons A. Ospdr9, which encodes a PDR-type ABC transporter, is induced by heavy metals, hypoxic stress and redox perturbations in rice roots. FEBS Lett. 2003:553(3):370-6.

47. Oda K, Otani M, Uraguchi S, Akihiro T, Fujiwara T. Rice ABCG43 is cd inducible and confers cd tolerance on yeast. Biosci Biotechnol Biochem. 2011;75(6):1211-3. 
48. Kim DY, Bovet L, Maeshima M, Martinoia E, Lee Y. The ABC transporter AtPDR8 is a cadmium extrusion pump conferring heavy metal resistance. Plant J. 2007;50(2):207-18.

49. Milner MJ, Seamon J, Craft E, Kochian LV. Transport properties of members of the ZIP family in plants and their role in Zn and Mn homeostasis. J Exp Bot. 2013;64(1):369-81.

50. Guerinot ML. The ZIP family of metal transporters. Biochim Biophys Acta. 2000;1465(1-2):190-8.

51. Li S, Zhou X, Huang Y, Zhu L, Zhang S, Zhao Y, Guo J, Chen J, Chen R. Identification and characterization of the zinc-regulated transporters, iron-regulated transporter-like protein (ZIP) gene family in maize. BMC Plant Biol. 2013;13:114.

52. Hanada K, Zou C, Lehti-Shiu MD, Shinozaki K, Shiu SH. Importance of lineage-specific expansion of plant tandem duplicates in the adaptive response to environmental stimuli. Plant Physiol. 2008;148(2):993-1003.

53. Rensing SA. Gene duplication as a driver of plant morphogenetic evolution. Curr Opin Plant Biol. 2014;17:43-8.

54. Panchy N, Lehti-Shiu M, Shiu SH. Evolution of gene duplication in plants. Plant Physiol. 2016;171(4):2294-316.

55. Ó Lochlainn S, Bowen HC, Fray RG, Hammond JP, King GJ, White PJ, Graham NS, Broadley MR. Tandem quadruplication of HMA4 in the zinc (Zn) and cadmium (cd) hyperaccumulator Noccaea caerulescens. PLoS One. 2011;6(3):e17814.

56. Nouet C, Charlier JB, Carnol M, Bosman B, Farnir F, Motte P, Hanikenne M. Functional analysis of the three HMA4 copies of the metal hyperaccumulator Arabidopsis halleri. J Exp Bot. 2015;66(19):5783-95.

57. Li L, Xu X, Chen C, Shen Z. Genome-wide characterization and expression analysis of the germinlike protein family in rice and Arabidopsis. Int J Mol Sci. 2016;17(10):1622

58. Liu Q, Yang J, Yan S, Zhang S, Zhao J, Wang W, Yang T, Wang X, Mao X, Dong J, et al. The germin-like protein OsGLP2-1 enhances resistance to fungal blast and bacterial blight in rice. Plant Mol Biol. 2016;92(4-5):411-23.

59. Banerjee J, Das N, Dey P, Maiti MK. Transgenically expressed rice germin-like protein 1 in tobacco causes hyper-accumulation of $\mathrm{H}_{2} \mathrm{O} 2$ and reinforcement of the cell wall components. Biochem Bioph Res Commun. 2010;402(4):637-43.

60. Rietz S, Bernsdorff FE, Cai D. Members of the germin-like protein family in Brassica napus are candidates for the initiation of an oxidative burst that impedes pathogenesis of Sclerotinia sclerotiorum. J Exp Bot. 2012;63(15):5507-19.

61. Tonnessen BW, Manosalva P, Lang JM, Baraoidan M, Bordeos A, Mauleon R, Oard J, Hulbert S, Leung H, Leach JE. Rice phenylalanine ammonia-lyase gene OsPAL4 is associated with broad spectrum disease resistance. Plant Mol Biol. 2015;87(3):273-86.

62. Zhang X, Gou M, Liu CJ. Arabidopsis Kelch repeat F-box proteins regulate phenylpropanoid biosynthesis via controlling the turnover of phenylalanine ammonia-lyase. Plant Cell. 2013;25(12):4994-5010.

63. Cass CL, Peraldi A, Dowd PF, Mottiar Y, Santoro N, Karlen SD, Bukhman YV, Foster CE, Thrower N, Bruno LC, et al. Effects of PHENYLALANINE AMMONIA LYASE (PAL) knockdown on cell wall composition, biomass digestibility, and biotic and abiotic stress responses in Brachypodium. J Exp Bot. 2015;66(14): 4317-35.

64. Izbianska K, Arasimowicz-Jelonek M, Deckert J. Phenylpropanoid pathway metabolites promote tolerance response of lupine roots to lead stress. Ecotox Environ Safe. 2014;110:61-7.

65. Liu G, Zhang K, Ai J, Deng X, Hong Y, Wang X. Patatin-related phospholipase a, pPLAllla, modulates the longitudinal growth of vegetative tissues and seeds in rice. J Exp Bot. 2015;66(21):6945-55.

66. Scherer GF, Ryu SB, Wang X, Matos AR, Heitz T. Patatin-related phospholipase a: nomenclature, subfamilies and functions in plants. Trends Plant Sci. 2010;15(12):693-700.

67. Matos AR, Gigon A, Laffray D, Petres S, Zuily-Fodil Y, Pham-Thi AT. Effects of progressive drought stress on the expression of patatin-like lipid acyl hydrolase genes in Arabidopsis leaves. Physiol Plant. 2008;134(1):110-20.

68. Ahmad P, Rasool S, Gul A, Sheikh SA, Akram NA, Ashraf M, Kazi AM, Gucel S. Jasmonates: multifunctional roles in stress tolerance. Front Plant Sci. 2016;7:813.

69. Howe GA, Schilmiller AL. Oxylipin metabolism in response to stress. Curr Opin Plant Biol. 2002;5(3):230-6

70. Luo ZB, He J, Polle A, Rennenberg H. Heavy metal accumulation and signal transduction in herbaceous and woody plants: paving the way for enhancing phytoremediation efficiency. Biotechnol Adv. 2016;34(6):1131-48.

71. Lin CY, Trinh NN, Fu SF, Hsiung YC, Chia LC, Lin CW, Huang HJ. Comparison of early transcriptome responses to copper and cadmium in rice roots. Plant Mol Biol. 2013;81(4-5):507-22.
72. Leng P, Yuan B, Guo Y. The role of abscisic acid in fruit ripening and responses to abiotic stress. J Exp Bot. 2014;65(16):4577-88.

73. de Ollas C, Dodd IC. Physiological impacts of ABA-JA interactions under water-limitation. Plant Mol Biol. 2016;91(6):641-50.

74. de Abreu Neto JB, Frei M. Microarray meta-analysis focused on the response of genes involved in redox homeostasis to diverse abiotic stresses in rice. Front Plant Sci. 2015;6:1260.

75. Cowan GH, Roberts AG, Jones S, Kumar P, Kalyandurg PB, Gil JF, Savenkov El, Hemsley PA, Torrance L. Potato mop-top virus co-opts the stress sensor HIPP26 for long-distance movement. Plant Physiol. 2018;176(3):2052-70.

76. Barth O, Vogt S, Uhlemann R, Zschiesche W, Humbeck K. Stress induced and nuclear localized HIPP26 from Arabidopsis thaliana interacts via its heavy metal associated domain with the drought stress related zinc finger transcription factor ATHB29. Plant Mol Biol. 2009;69(1-2):213-26.

77. Hu H, Dai M, Yao J, Xiao B, Li X, Zhang Q, Xiong L. Overexpressing a NAM, ATAF, and CUC (NAC) transcription factor enhances drought resistance and salt tolerance in rice. Proc Natl Acad Sci U S A. 2006;103(35):12987-92.

78. Liu G, Li X, Jin S, Liu X, Zhu L, Nie Y, Zhang X. Overexpression of rice NAC gene SNAC1 improves drought and salt tolerance by enhancing root development and reducing transpiration rate in transgenic cotton. PLoS One. 2014;9(1):e86895.

79. Lu M, Ying S, Zhang DF, Shi YS, Song YC, Wang TY, Li Y. A maize stressresponsive NAC transcription factor, ZmSNAC1, confers enhanced tolerance to dehydration in transgenic Arabidopsis. Plant Cell Rep. 2012;31(9):1701-11.

80. Ramesh SA, Tyerman SD, Gilliham M, Xu B. Y-Aminobutyric acid (GABA) signalling in plants. Cell Mol Life Sci. 2017:74(9):1577-603.

81. Krasensky J, Jonak C. Drought, salt, and temperature stress-induced metabolic rearrangements and regulatory networks. J Exp Bot. 2012;63(4): 1593-608.

82. Mekonnen DW, Flugge UI, Ludewig F. Gamma-aminobutyric acid depletion affects stomata closure and drought tolerance of Arabidopsis thaliana. Plant Sci. 2016;245:25-34.

83. Ramesh SA, Tyerman SD, Xu B, Bose J, Kaur S, Conn V, Domingos P, Ullah S, Wege $S$, Shabala $S$, et al. GABA signalling modulates plant growth by directly regulating the activity of plant-specific anion transporters. Nat Commun. 2015;6:7879

84. Carillo P. GABA shunt in durum wheat. Front Plant Sci. 2018:9:100.

85. Kang SM, Radhakrishnan R, You YH, Khan AL, Lee KE, Lee JD, Lee IJ. Enterobacter asburiae KE17 association regulates physiological changes and mitigates the toxic effects of heavy metals in soybean. Plant Biol (Stuttg). 2015;17(5):1013-22.

86. Dubey S, Misra P, Dwivedi S, Chatterjee S, Bag SK, Mantri S, Asif MH, Rai A Kumar S, Shri M, et al. Transcriptomic and metabolomic shifts in rice roots in response to $\mathrm{Cr}(\mathrm{VI})$ stress. BMC Genomics. 2010;11:648.

87. Hijaz F, Nehela Y, Killiny N. Application of gamma-aminobutyric acid increased the level of phytohormones in Citrus sinensis. Planta. 2018;248:909.

88. Ma X, Zhu C, Yang N, Gan L, Xia K. Y-Aminobutyric acid addition alleviates ammonium toxicity by limiting ammonium accumulation in rice (Oryza sativa) seedlings. Physiol Plant. 2016;158(4):389-401.

89. Wang Y, Gu W, Meng Y, Xie T, Li L, Li J, Wei S. Y-Aminobutyric acid imparts partial protection from salt stress injury to maize seedlings by improving photosynthesis and upregulating osmoprotectants and antioxidants. Sci Rep. 2017;7:43609.

90. Yu GH, Zou J, Feng J, Peng XB, Wu JY, Wu YL, Palanivelu R, Sun MX. Exogenous $\gamma$-aminobutyric acid (GABA) affects pollen tube growth via modulating putative $\mathrm{Ca}^{2+}$-permeable membrane channels and is coupled to negative regulation on glutamate decarboxylase. J Exp Bot. 2014;65(12):3235-48.

91. Li R, Li X, Fu D, Zhu B, Tian H, Luo Y, Zhu H. Multiplexed CRISPR/Cas9mediated metabolic engineering of $\gamma$-aminobutyric acid levels in Solanum lycopersicum. Plant Biotechnol J. 2018;16(2):415-27.

92. Takayama M, Matsukura C, Ariizumi T, Ezura H. Activating glutamate decarboxylase activity by removing the autoinhibitory domain leads to hyper $\gamma$-aminobutyric acid (GABA) accumulation in tomato fruit. Plant Cell Rep. 2017;36(1):103-16.

93. Akama K, Takaiwa F. C-terminal extension of rice glutamate decarboxylase (OsGAD2) functions as an autoinhibitory domain and overexpression of a truncated mutant results in the accumulation of extremely high levels of GABA in plant cells. J Exp Bot. 2007:58(10):2699-707.

94. Rabara RC, Tripathi P, Reese RN, Rushton DL, Alexander D, Timko MP, Shen QJ, Rushton PJ. Tobacco drought stress responses reveal new targets for Solanaceae crop improvement. BMC Genomics. 2015;16:484. 